\title{
Advances in molecular imaging for breast cancer detection and characterization
}

\author{
Jennifer M Specht* ${ }^{* 1,2}$ and David A Mankoff',2
}

\begin{abstract}
Advances in our ability to assay molecular processes, including gene expression, protein expression, and molecular and cellular biochemistry, have fueled advances in our understanding of breast cancer biology and have led to the identification of new treatments for patients with breast cancer. The ability to measure biologic processes without perturbing them in vivo allows the opportunity to better characterize tumor biology and to assess how biologic and cytotoxic therapies alter critical pathways of tumor response and resistance. By accurately characterizing tumor properties and biologic processes, molecular imaging plays an increasing role in breast cancer science, clinical care in diagnosis and staging, assessment of therapeutic targets, and evaluation of responses to therapies. This review describes the current role and potential of molecular imaging modalities for detection and characterization of breast cancer and focuses primarily on radionuclide-based methods.
\end{abstract}

\section{Introduction}

Progress in the ability to assay molecular processes, including gene expression, protein expression, and molecular and cellular biochemistry, has fueled advances in our understanding of breast cancer biology and has led to the identification of new treatments for patients with breast cancer. The ability to measure biologic processes without perturbing them in vivo by using advanced imaging methods provides the opportunity to better characterize tumor biology and to assess how biologic and cytotoxic therapies alter critical pathways of tumor response and resistance. Traditionally, imaging has relied

*Correspondence: jspecht@uw.edu

'Division of Medical Oncology, University of Washington, Seattle Cancer Care Alliance, 825 Eastlake Avenue East, G3-630, Seattle, WA 98109, USA

Full list of author information is available at the end of the article on structural and anatomic features to detect breast cancer and determine its extent (that is, anatomic imaging). By contrast, molecular imaging modalities allow for imaging of regional biochemistry and molecular biology. Molecular imaging further provides information complementary to that obtained by traditional, tissue-based assay methods. By accurately characterizing tumor properties and biologic processes, molecular imaging plays a pivotal role in breast cancer science and clinical care in diagnosis and staging, assessment of therapeutic targets, and evaluation of responses to therapies [1]. This review describes the current role and potential of molecular imaging modalities for detection and characterization of breast cancer and focuses specifically on radionuclide imaging techniques.

\section{Overview of molecular imaging methods applied to breast cancer}

Most imaging modalities used in clinical practice are largely anatomic in nature, using tissue features such as size, shape, and density to identify breast cancer. Anatomic imaging modalities commonly used for detecting both primary breast cancer and metastatic breast cancer (MBC) include mammography, $\mathrm{x}$-ray computed tomography $(\mathrm{CT})$, ultrasound, and magnetic resonance imaging (MRI). Alternatively, molecular imaging measures regional in vivo biochemical, cellular, and molecular properties of tumors and normal tissues. By targeting underlying molecular processes, molecular imaging modalities can image biologic processes specific to cancer and this may aid in cancer detection and characterization and complement traditional anatomic imaging methods. Table 1 summarizes current molecular imaging modalities that have been used in clinical practice and in human research settings applied to breast cancer. In this review, we focus primarily on radionuclide-based molecular imaging methods but briefly mention applications of other molecular imaging modalities.

Radionuclide imaging relies on the use of imaging probes tagged with radioactive nuclei [2]. Positionsensitive radiation detectors identify emitted photons and generate images of regional radiopharmaceutical concentration. Radionuclide imaging can be performed 
Table 1. Molecular imaging for breast cancer

\begin{tabular}{|c|c|c|c|}
\hline Modality & Indication & Advantages & Disadvantages \\
\hline \multicolumn{4}{|l|}{ Radionuclide imaging } \\
\hline Positron emission tomography & $\begin{array}{l}\text { Detection } \\
\text { Response evaluation } \\
\text { Tumor characterization }\end{array}$ & $\begin{array}{l}\text { Wide range of molecular imaging probes } \\
\text { Tracer imaging without perturbing } \\
\text { biologic system }\end{array}$ & $\begin{array}{l}\text { Limited spatial resolution (improved } \\
\text { with use of non-contrast computed } \\
\text { tomography) } \\
\text { Some radiation exposure }\end{array}$ \\
\hline $\begin{array}{l}\text { Positron emission } \\
\text { mammography }\end{array}$ & $\begin{array}{l}\text { Detection } \\
\text { Tumor characterization }\end{array}$ & $\begin{array}{l}\text { More sensitive for smaller tumors } \\
\text { Higher spatial resolution }\end{array}$ & $\begin{array}{l}\text { Increased radiation dose } \\
\text { Visualization of posterior lesions } \\
\text { Variable uptake of } \\
{ }^{18} \text { F-fluorodeoxyglucose (FDG) in small } \\
\text { and less metabolically active tumors }\end{array}$ \\
\hline Breast-specific gamma imaging & Detection & $\begin{array}{l}\text { More sensitive for smaller tumors } \\
\text { Heavy compression of breast tissue } \\
\text { not required }\end{array}$ & $\begin{array}{l}\text { Associated with radiation exposure } \\
\text { Best combined with anatomic imaging } \\
\text { (mammography) for optimal screening } \\
\text { Longer imaging time } \\
\text { Some radiation exposure }\end{array}$ \\
\hline \multicolumn{4}{|l|}{ Magnetic resonance } \\
\hline $\begin{array}{l}\text { Magnetic resonance imaging } \\
\text { (MRI), especially dynamic } \\
\text { contrast-enhanced MRI and } \\
\text { targeted contrast agents }\end{array}$ & Tumor characterization & $\begin{array}{l}\text { Quantification of tumor perfusion } \\
\text { and tumor capillary permeability }\end{array}$ & $\begin{array}{l}\text { Confined space } \\
\text { Contrast design limited by need for } \\
\text { magnetic atom }\end{array}$ \\
\hline Magnetic resonance spectroscopy & Tumor characterization & $\begin{array}{l}\text { Can measure wide range of molecules } \\
\text { No contrast necessary }\end{array}$ & $\begin{array}{l}\text { Limited spatial resolution } \\
\text { Challenging to obtain high-quality } \\
\text { spectra in routine imaging }\end{array}$ \\
\hline $\begin{array}{l}\text { Ultrasound, especially with } \\
\text { contrast enhancement }\end{array}$ & $\begin{array}{l}\text { Detection } \\
\text { Tumor characterization }\end{array}$ & $\begin{array}{l}\text { Highly portable, inexpensive } \\
\text { Molecular microbubble agents possible }\end{array}$ & $\begin{array}{l}\text { Operator dependence } \\
\text { Contrast agents confined to vascular } \\
\text { space thus far }\end{array}$ \\
\hline Optical imaging & Tumor characterization & $\begin{array}{l}\text { Inexpensive, highly portable, and does } \\
\text { not necessarily require a contrast agent }\end{array}$ & $\begin{array}{l}\text { Limited depth penetration, challenging } \\
\text { spatial localization, and operator } \\
\text { dependence }\end{array}$ \\
\hline
\end{tabular}

by using single-photon-emitting isotopes and is termed single-photon emission CT (SPECT), in which images are collected and reconstructed as tomographic images. The most commonly used single-photon radiopharmaceutical used for breast imaging is ${ }^{99 \mathrm{~m}} \mathrm{Tc}$-sestamibi (MIBI). More recently, high-resolution, small-field-of-view $\gamma$ cameras specific to breast imaging, sometimes called breast-specific $\gamma$ imaging (BSGI) or molecular breast imaging, have been developed $[3,4]$.

Another important class of radionuclide imaging procedures uses positron-emitting isotopes and is termed positron emission tomography (PET). Compared with SPECT, PET offers the potential for better spatial resolution, a more accurate image quantification, and a wide range of possible imaging probes. PET has proven to be a very useful tool in the staging of advanced breast cancer, in assessing response to therapy, and is widely used in clinical care in the form of PET-CT. Although a wide range of radiopharmaceutical tracers have been developed for use with PET, most breast cancer imaging to date has been done with ${ }^{18} \mathrm{~F}$-fluorodeoxyglucose (FDG) [5]. FDG is a glucose analog that is transported via glucose transporters into the cells, where it is phosphorylated by hexokinase in proportion to the rate of glucose phosphorylation. Further catabolism of FDG is not possible, because it lacks a hydroxyl group at the C-2 position. FDG becomes 'metabolically trapped' in tumor cells at a rate proportional to glucose utilization. FDG PET therefore provides an effective way to measure glucose metabolism. Most PET imaging is performed by using devices designed for torso imaging; however, dedicated devices designed specifically for positron emission of the breast, termed positron emission mammography (PEM), represent a promising breast imaging modality [6].

Of other modalities used for molecular imaging, MRI is the most widely used in current breast cancer practice [7]. MRI relies upon the interaction of atomic nuclei with radiofrequency signals in the presence of strong magnetic fields and can generate high-resolution, three-dimensional images with excellent soft tissue contrast. In current clinical practice, MRI is most often used for anatomic imaging; however, with a more detailed analysis of contrast enhancement kinetics or the use of contrast agents that are more molecularly targeted or both, MRI can be used to measure physiologic and molecular properties [8-11]. Magnetic resonance methods can also be used to measure the regional concentration of specific biochemical species (for example, products of metabolism or membrane lipids, often termed magnetic resonance 
spectroscopy (MRS) or magnetic resonance spectroscopic imaging) [12]. For example, increased levels of choline in breast cancer versus normal breast tissue can be measured by MRS, and changes in choline levels with treatment can provide an early indication of therapeutic efficacy [13].

Other molecular imaging modalities that have been tested in breast cancer include optical imaging and contrast-enhanced ultrasound. Optical imaging relies on visible light to generate images that reflect breast tissue properties [14]. Optical imaging can also employ molecularly targeted optical contrast agents for a more specific delineation of molecular features. Pilot studies suggest that optical imaging methods (for example, diffuse optical spectroscopy) can provide an early readout of treatment efficacy [15], and larger, multicenter trials of optical imaging are under way. Though currently used as a largely anatomic imaging method in breast cancer, ultrasound can provide molecular information through the use molecule-labeled microbubble contrast agents [16]. Molecularly targeted contrast ultrasound is largely at the preclinical stage of investigation; however, some early trials of target ultrasound contrast agents in patients are under way.

\section{Radionuclide molecular imaging for primary breast cancer detection and diagnosis}

Anatomic imaging is widely used in breast cancer screening and detection, and mammography is still the gold standard. While anatomic techniques continue to evolve with improvements in spatial resolution and image quality (examples include computer-aided detection and digital mammography as well as other anatomic imaging methods such as MRI and ultrasound), molecular imaging may provide a more specific targeting of breast cancer tissue and greater contrast between tumor and normal tissue. We briefly review studies that use radionuclide methods for primary breast cancer detection and diagnosis.

\section{Single-photon radionuclide breast imaging}

The most commonly used single-photon radiopharmaceutical used for breast imaging is MIBI. MIBI is a cationic compound whose uptake and retention in the breast tumor are dependent on regional blood flow, plasma, and mitrochondrial membrane potential $[17,18]$. MIBI retention in tumors may also be affected by the efflux transporter, P-glycopotein [19]. Early breast imaging using MIBI used standard nuclear medicine $\gamma$ cameras and was termed scintimammography. A metaanalysis by Liberman and colleagues [20] on the diagnostic accuracy of scintimammography found a sensitivity of $85 \%$, a specificity of $87 \%$, a positive predictive value of $88 \%$, a negative predictive value of $81 \%$, and an accuracy of $86 \%$. The primary limitations of this approach were poor detection of breast lesions of less than $1 \mathrm{~cm}$, lower sensitivity in non-palpable lesions, and some falsepositive uptake in benign breast lesions, inflammation, hematoma, and fat necrosis. Scintimammography generated early interest in clinical breast cancer diagnosis, but the problems noted above limited its clinical use [21].

More recently, high-resolution, small-field-of-view $\gamma$ cameras specific to breast imaging, sometimes called BSGI or molecular breast imaging, have been developed $[3,4]$. With the use of breast-specific $\gamma$ cameras, lesions of less than $1 \mathrm{~cm}$ and non-palpable and in situ carcinoma can be visualized [4]. Because the uptake of MIBI is independent of breast density, BSGI may serve as a valuable imaging technique for women with mammographically dense breasts. In one study, 1,007 patients with heterogeneously or extremely dense breasts by mammography were screened with mammography and BSGI. The addition of BSGI to mammography significantly increased detection of node-negative breast cancer in dense breasts by 7.5 per 1,000 women screened over mammography and was able to detect cancers as small as $0.4 \mathrm{~cm}$ [22]. Limitations to BSGI include the long imaging time (four 10-minute images), the radiation dose associated with injection of the MIBI, and the uncertain ability of BSGI to detect breast microcalcifications [23]. Through optimization of detector technology and innovative noise reduction algorithms, it is anticipated that the dose of radiation required for BSGI could be comparable to that associated with a screening mammogram. BSGI may have a role in the evaluation of patients for whom breast MRI is contraindicated. Finally, although MIBI is the principal radiopharmaceutical used with BSGI to date, a number of other radiopharmaceuticals that target other facets of cancer biology are in development [23]. BSGI has a limited role in clinical practice; however, it is being actively investigated in clinical trials for breast cancer detection and characterization.

\section{Positron emission tomography breast imaging}

Compared with SPECT, PET offers the potential for better spatial resolution, a more accurate image quantification, and a wide range of possible imaging probes. The combination of PET with CT yields co-registered molecular and anatomic images and the opportunity to image molecular biology and anatomy simultaneously [24-27]. Although several radiopharmaceutical tracers for use with PET exist, only two are approved in the US for clinical use in cancer: FDG and ${ }^{18} \mathrm{~F}$-fluoride, the latter of which is used primarily for bone imaging. Almost all clinical cancer imaging performed currently is done using FDG. Because accelerated glycolysis is a key feature of many cancers (including breast cancer), FDG generally has high tumor uptake compared with background in 
most normal tissues (including the normal breast), making it an attractive agent for cancer detection [5]. Studies have suggested that the degree of FDG uptake in breast cancer is variable and correlated with several phenotypic features such as histologic type (higher uptake in ductal versus lobular cancers), tumor histologic grade (higher uptake in higher grade), steroid receptor expression (higher uptake in steroid receptor-negative tumors), and indices of cellular proliferation (higher uptake in the more proliferative tumors) $[28,29]$.

Early studies using whole-body PET imaging devices showed that FDG PET has high sensitivity and specificity for the detection of larger, palpable breast cancers [30]. Overall, the sensitivity of FDG PET using devices designed for whole-body imaging to detect primary breast cancer was $64 \%$ to $96 \%$, specificity was $73 \%$ to $100 \%$, positive predictive value was $81 \%$ to $100 \%$, and negative predictive value was $52 \%$ to $89 \%$ [30]. However, sensitivity for smaller and non-palpable lesions was more limited, as was the detection of low-grade or non-invasive cancers [31], which are of significant importance for a breast cancer detection modality. There has therefore been fairly widespread agreement that whole-body FDG PET does not have a clinical role in detecting primary breast cancer, nor is it an alternative to histologic sampling to establish or exclude a primary breast cancer, because of the well-documented inability of FDG PET to consistently demonstrate small and low-grade lesions [31].

\section{Positron emission mammography breast imaging}

To overcome the limitations of whole-body FDG PET, dedicated devices for positron emission imaging designed to image the breast only, often termed PEM, have been developed. The advantages of PEM over whole-body FDG PET include higher spatial resolution, reduced attenuation, and possibly lower radiopharmaceutical doses [6]. By mounting the positron detectors on a mammography unit, anatomical and molecular images are co-registered in a fashion analogous to PET-CT (Figure 1). The correlation of mammographic and PEM images allows for PEM-guided biopsy [32].

PEM allows for detection of breast lesions as small as $2 \mathrm{~mm}$ and small foci of ductal carcinoma in situ. The results of a multicenter study examining the efficacy of PEM reported $91 \%$ sensitivity and $93 \%$ specificity [33]. The reported limitations of PEM include a radiation dose that is higher than that of a mammogram [34], potential difficulty imaging breast lesions that are in a posterior location, the variable uptake of FDG in small and less metabolically active tumors, and false-positive findings from prior biopsy $[33,35]$. In a large trial of patients who had newly diagnosed early breast cancer and who were undergoing conventional imaging, PEM, and MRI,

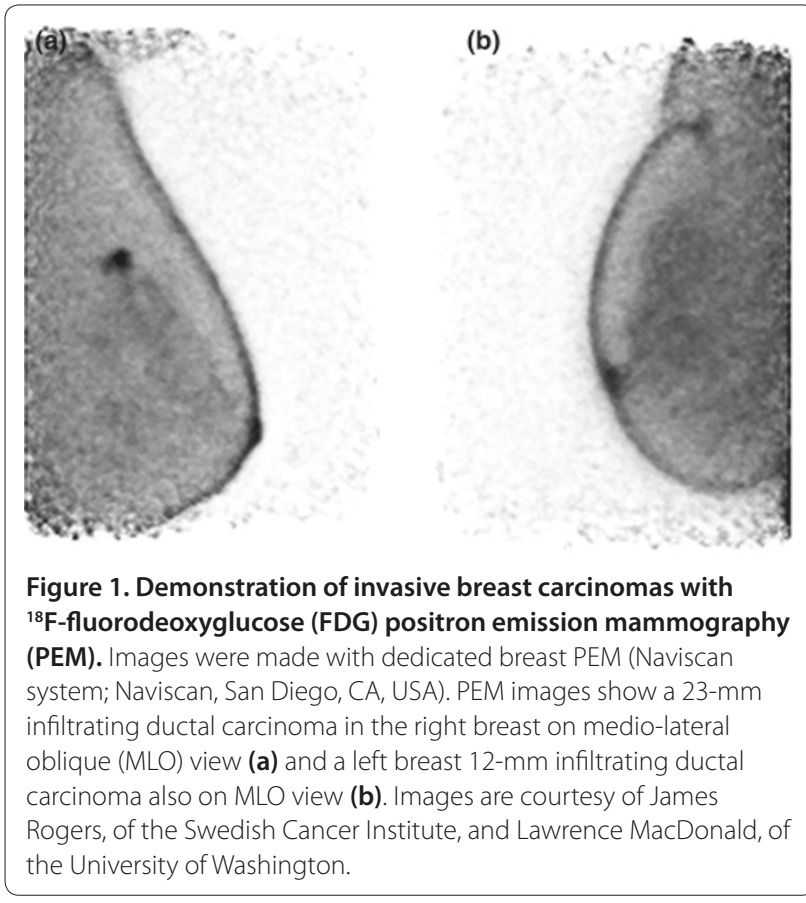

conventional imaging plus PEM depicted additional disease in $14 \%$ of patients, which is not significantly different from the detection achieved with conventional imaging and MRI $(15 \%, P=0.26)$. PEM showed improved specificity compared with MRI and may be less likely to prompt unnecessary biopsies and may be an alternative for individuals who cannot tolerate MRI [36]. Currently, PEM uses an approved radionuclide tracer, namely FDG, but is not considered a routine diagnostic modality; however, clinical trials to better define its clinical role are ongoing.

\section{Breast cancer staging and response evaluation}

Most FDG PET performed in current clinical practice is performed as whole-body PET-CT, largely for staging and response evaluation. Early studies demonstrating abnormal FDG uptake on PET in metastatic axillary lymph nodes of patients with breast cancer $[37,38]$ prompted a prospective multicenter trial to evaluate the ability to stage the axilla with FDG PET before surgery [39]. The results of this study, which included patients with earlier-stage disease of the type more typically found with modern screening methods, were disappointing. Overall, FDG PET was $61 \%$ sensitive and $80 \%$ specific for axillary metastases. This trial and subsequent studies showed that sensitivity of FDG PET for axillary metastases in early-stage breast cancer was not sufficient to preclude tissue sampling, usually performed with sentinel lymph node mapping and biopsy, which is highly sensitive for even microscopic foci of tumor. There is currently no clinical role for routine FDG PET axillary 
staging in women with newly diagnosed, early-stage breast cancer. Owing to the low likelihood of distant metastases and the not insignificant rate of false-positive findings in low-risk patient populations, whole-body FDG PET or PET-CT is not recommended for systemic staging in breast cancer patients with early-stage disease [40].

Although FDG PET or PET-CT is not recommended in the staging evaluation of patients with early-stage breast cancer, numerous studies have supported the role of FDG PET and PET-CT in regional and systemic staging for patients with locally advanced breast cancer (LABC) [41-43]. In the setting of LABC, the risk of axillary and internal mammary node metastases is higher, as is the risk for occult sites of malignant disease which may affect therapeutic recommendations. FDG PET can also be useful in assessing cancer spread to the internal mammary node chain. In patients with LABC, FDG uptake in the internal mammary nodes is frequently demonstrated (25\%) and such uptake is predictive of both the likelihood and pattern of treatment failure [44]. A recent, randomized clinical trial evaluating the role of regional nodal radiation (including internal mammary nodes) in patients treated with breast-conserving surgical therapy showed improvement in disease-free survival with comprehensive nodal radiation [45]. Such findings emphasize the importance of identification of regional nodal disease in breast cancer.

FDG PET-CT is an accepted and reimbursed staging tool for patients with recurrent, suspected, or documented stage IV disease and in these settings has been shown to be both sensitive and specific for accurately determining the extent of disease [21,46-49]. It is important to remember that the $\mathrm{CT}$ obtained for attenuation correction in a clinical PET-CT is not necessarily the same as a dedicated, diagnostic, contrast CT that is breath-held.

Serial FDG PET has been widely studied as a method for assessing tumor response to neoadjuvant chemotherapy by using comparison with histopathology assessment of response from the pathology specimen as the gold standard. Studies evaluating change in FDG uptake early in the course of neoadjuvant therapy demonstrate that early declines in FDG uptake are predictive of pathologic response to therapy [50-52]. Molecular imaging by FDG PET may serve as an early predictor of chemotherapy response and, perhaps more importantly, accurately identify those tumors with lack of response, which is clinically relevant as the number of options for systemic therapies increases.

Molecular imaging modalities, primarily FDG PET, have also been used to evaluate response to therapy in metastatic (stage IV) breast cancer. Similar to observations made in the setting of neoadjuvant chemotherapy, disease response is typically accompanied by substantial declines in FDG uptake by PET, typically $50 \%$ or more from pre-therapy baseline values $[53,54]$.

The standard approach for response evaluation in $\mathrm{MBC}$ continues to rely on anatomic imaging and changes in tumor size by using standard criteria such as Response Evaluation Criteria in Solid Tumors (RECIST) and anatomic imaging, mostly $\mathrm{CT}[55,56]$. The vast majority of clinical trials in MBC rely on RECIST to assess response and often have eligibility that is dependent on measurable disease by RECIST. While this approach works well for some disease sites like the lungs and liver, size-based anatomic imaging response for soft tissue disease and, particularly, bone metastases remains challenging and an opportunity for incorporation of molecular imaging modalities. Treatment stratification based on metabolic response by PET (PET Response Criteria in Solid Tumors, or PERCIST) has been proposed [57] and awaits validation but is an important advance in molecular imaging.

A particularly vexing clinical problem for breast cancer clinicians is the evaluation of response of bone metastases [58]. Bone is the most common site of breast cancer metastasis. Bone metastases may be detected by bone scintigraphy and MRI, which depict tumor sites largely on the basis of the tumor's effect on adjacent bone. However, in the setting of serial imaging to assess response, these techniques, particularly bone scintigraphy, can be problematic because of a lag in response and potential for 'flare' or transient increase in uptake in response to successful therapy [59]. Patients with boneonly or bone-dominant MBC are often excluded because of the lack of measurable disease.

Early studies have evaluated the role of serial FDG PET as an accurate means for assessing bone metastasis response as glucose metabolism measured in the bone metastasis itself might provide a more direct assessment of treatment response. The earliest studies showed that changes in FDG PET during therapy correlated with changes in serum tumor markers [60] and that percentage change in standard uptake value (SUV) predicted time to progression, a more robust clinical endpoint. Additionally, a higher initial SUV predicted a shorter time to skeleton-related events such as pathologic fracture, hypercalcemia, or need for radiation [61]. The combination of metabolic and anatomic features using PET-CT provides even greater insight. Tateishi and colleagues [62] showed that duration of response in bone-dominant MBC was associated with a decline in FDG PET SUV and an increase in sclerosis (a sign of bone 'healing' in response to therapy) as assessed by CT.

Breast cancer bone metastases present with a mixture of phenotypes ranging from osteoblastic to osteolytic lesions. Whereas FDG PET is a sensitive measure of 
osteolytic bone destruction, bone scintography using ${ }^{99 \mathrm{~m}} \mathrm{Tc}$-methylene diphosphonate (MDP) or ${ }^{18} \mathrm{~F}$-fluoride PET, which measures bone mineral deposition, is a preferred method for detection of osteoblastic lesions [63] and may offer some advantages for measuring response of these lesions, which can be difficult to visualize on FDG PET. Measurement of bone turnover kinetics by dynamic ${ }^{18} \mathrm{~F}$-fluoride PET has been shown to be feasible and offers the opportunity for quantitative assessment of bone metastasis response to therapy [64]. The prospective evaluation of the combination of ${ }^{18} \mathrm{~F}$ fluoride and FDG PET imaging may allow for validation of these imaging modalities as biomarkers for bone metastasis response that can be validated as endpoints for clinical trials (RECIST-like criteria for bone metastases) and shed light on the physiology of the breast cancer cells and their effects on adjacent bone turnover and thus may provide insights into novel therapies for bone metastases. Both FDG and ${ }^{18} \mathrm{~F}$-fluoride PET are approved tracers with increasing use in clinical response evaluation in the setting of MBC, especially in the setting of bone-dominant disease.

\section{Molecular imaging for breast cancer characterization}

Molecular imaging is ideally suited to measure in vivo tumor biology related to basic molecular and cellular processes such as metabolism, biosynthesis, cell proliferation, and cell death. This use of molecular imaging to elucidate mechanisms of tumor response and resistance and translation of observations from preclinical systems to patients is among the most exciting applications of molecular imaging. Given the difficulty in assaying some of these processes by tissue sampling, molecular imaging provides a unique and quantitative measure of important properties that may be assessed only in vivo. Molecular imaging thus can play an important role in directing breast cancer treatment by identifying regional target expression, documenting drug delivery, and measuring early pharmacodynamic responses to targeted therapy [65]. Selected examples of molecular imaging applied to understanding in vivo tumor biology, protein expression, and the tumor microenvironment are reviewed in this section. We emphasize that, although they have undergone preliminary testing in humans, almost all of the methods outlined in this section are investigational and have been tested only in small, single-center studies. The path to a more widespread availability and possible clinical use involves a number of steps that include commercialization of radiopharmaceutical production, rigorous prospective clinical trials, and regulatory approval. Below, we describe the current status of each example as well as any progress toward a more widespread availability.
Tumor perfusion is one of the earliest physiologic properties to be measured by molecular imaging, and advances in methodology have led to increasingly quantitative approaches. Measurement of freely diffusible imaging probes such as ${ }^{15} \mathrm{O}$-water by PET is a robust quantitative measure of tumor blood flow. Studies by our group have shown that breast tumor blood flow and metabolism in $\mathrm{LABC}$ as evaluated by ${ }^{15} \mathrm{O}$-water and FDG dynamic PET imaging are highly variable and that declines in blood flow and metabolism are predictive of response and survival in patients receiving neoadjuvant chemotherapy [66-68]. The studies suggested that changes in perfusion were highly predictive of response and subsequent relapse and were confirmed by other studies using dynamic contrast-enhanced MRI (DCEMRI) to measure perfusion changes [8,69,70]. Combined metabolism/perfusion imaging also found that LABC tumors with pre-therapy flow-metabolism mismatch (high ratio of metabolic rate of FDG to blood flow) were most resistant to therapy, predicting a low likelihood of pathologic complete response and a high likelihood of early disease relapse $[66,67]$. In multivariate models, PET measures of predicted relapse and survival independently of other established prognostic measures, including pathologic complete response and post-therapy nodal status, and other investigators have confirmed the predictive value of metabolism/perfusion imaging in breast cancer and other tumors [71].

${ }^{15} \mathrm{O}$-water is an investigational tracer with a very short half-life ( 2 minutes) that requires an on-site cyclotron and rapid transit to the imaging site. Other modalities that provide measures of regional perfusion include DCE-MRI (often used to measure the effect of antiangiogenic agents) [9,10], Doppler ultrasound [72,73], and optical imaging [15]. Agents for specific imaging of angiogenesis (for example, ${ }^{18} \mathrm{~F}$-galacto arginine-glycineaspartate (RGD) peptide) have also undergone early testing in humans [74]. Combining measures of metabolism and perfusion (for example, FDG PET and DCE-MRI) may be useful to evaluate the effect of anti-vascular therapy combined with chemotherapy (Figure 2).

Breast tumor metabolism has also been widely studied with molecular imaging. Besides glucose metabolism measured by FDG PET, other PET pharmaceuticals can be used to measure other aspects of metabolism, including regional oxygen consumption using ${ }^{15} \mathrm{O}-\mathrm{O}_{2}$ inhalation and lipid metabolism using agents such as ${ }^{11} \mathrm{C}$-choline $[5,75]$. MRS can also evaluate tumor metabolism by measuring concentrations of specific metabolites. Promising studies have used MRS to measure regional choline levels to characterize breast tumors [12]. For example, Moestue and colleagues [76] reported on distinct patterns of choline metabolism which are associated with different gene expression profiles in luminal and 


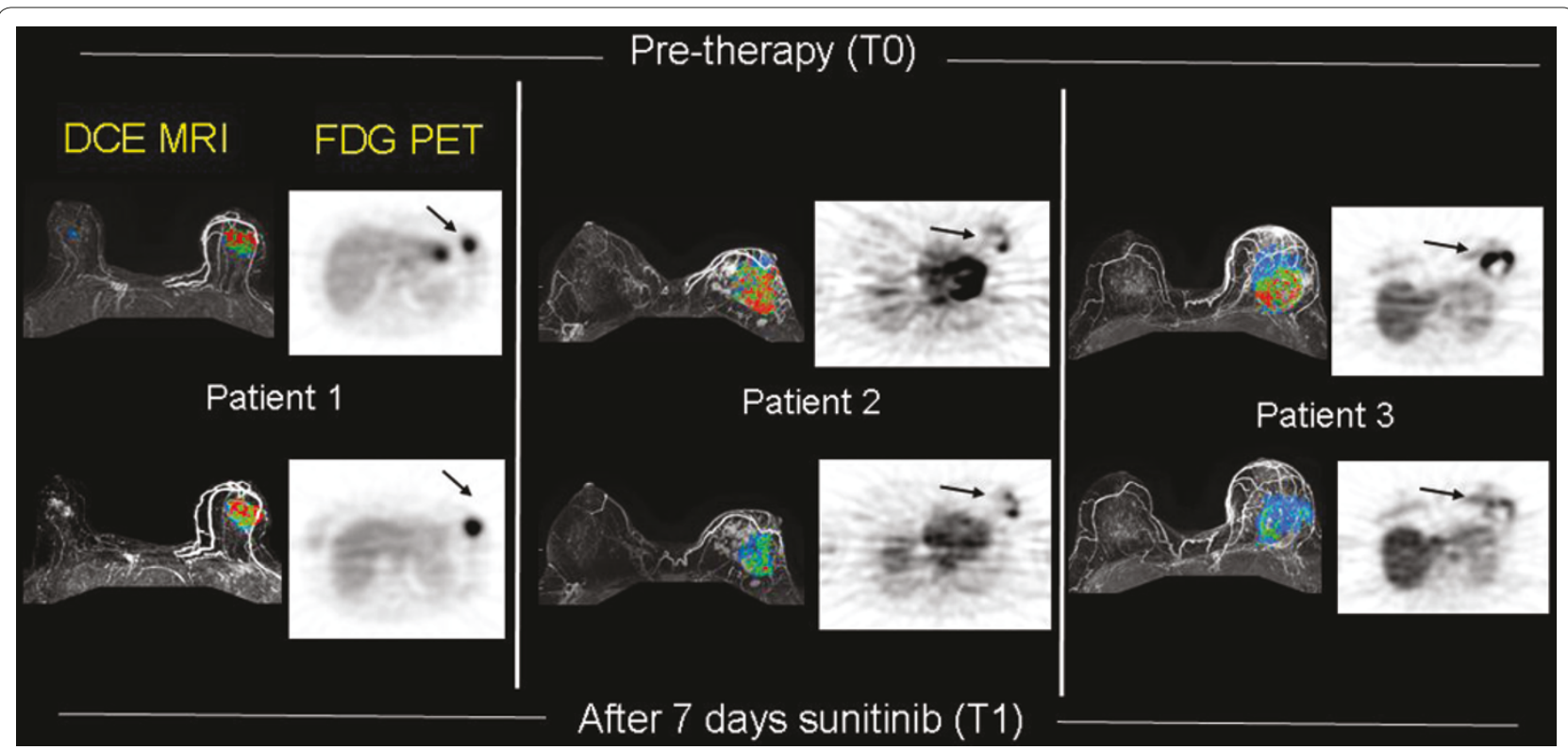

Figure 2. Targeting tumor vasculature: sunitinib. Dynamic contrast-enhanced magnetic resonance imaging (DCE-MRI) (left) and ${ }^{18}$ F-fluorodeoxyglucose (FDG) positron emission tomography (PET) images (right) before therapy (top) and after 1 week of sunitinib (bottom). DCE-MRI studies show gray-scale images with color-coded regional perfusion (signal enhancement ratio, or SER) superimposed. Red indicates high levels of perfusion, and blue indicates lower levels. DCE-MRI and FDG PET with kinetic analysis were used to monitor breast cancer response to neoadjuvant sunitinib and metronomic chemotherapy.

basal-like breast cancers, and serial choline levels measured by MRS provide an early indicator of treatment response [13].

Aberrant cellular proliferation is a fundamental property of cancer, including breast cancer [77]. Historically, ${ }^{14} \mathrm{C}$ - and ${ }^{3} \mathrm{H}$-thymidine have been important methods for measuring cellular proliferation through tissue sampling dating back more than 40 years [78]. More recently, Ki-67 (MIB-1) has provided a method of assessing breast tumor proliferation by immunohistochemistry and is commonly used in clinical practice [79]. A decline in Ki-67 assessed in serial breast tissue samples is an established prognostic marker, particularly in the setting of neoadjuvant endocrine therapy for breast cancer [80,81]. Early studies demonstrated the feasibility of PET imaging to measure cellular proliferation using ${ }^{11} \mathrm{C}$-thymidine [82]; however, the short half-life of ${ }^{11} \mathrm{C}$ (approximately 20 minutes) requires an on-site cyclotron and limits a more widespread availability. More recent work using thymidine analogs labeled with ${ }^{18} \mathrm{~F}$ (half-life of 109 minutes), specifically ${ }^{18} \mathrm{~F}$-fluorothymidine (FLT), has undergone considerable advances in recent years. FLT PET appears promising for measuring early effects of therapy on breast cancer growth $[83,84]$ and has been validated against an in vitro assay of proliferation [85]. Currently, the American College of Radiology Imaging Network is completing a multicenter neoadjuvant imaging trial that will evaluate the relationship between FLT uptake parameters and pathologic complete response of the primary tumor to neoadjuvant chemotherapy in patients with LABC [86]. FLT PET is also still an investigational tracer; however, a commercial supply network for FLT in the US and a National Cancer Institute-held (NCI-held) investigational new drug (IND) will lead to greater use in clinical trials and possible clinical use.

The ability to measure the expression of specific proteins that are gene products associated with breast cancer has led to important advances in breast cancer treatment. Examples include the archetypes of 'targeted therapy', the estrogen receptor (ER), a target for endocrine therapy [87], and human epidermal growth factor receptor 2 (HER2) [88]. Molecular imaging has also been applied to measuring specific protein expression $[89,90]$. Advantages of imaging include its non-invasiveness, the ability to measure receptor expression in the entire disease burden, and the potential for serial studies of in vivo drug effects on the target. Most of the work in this area of breast cancer research has been done for steroid receptors, particularly ER. The most successful ER imaging radiopharmaceutical is $16 \alpha-\left[{ }^{18} \mathrm{~F}\right]$-fluoro- $17 \beta$ estradiol (FES) [91]. FES has binding characteristics similar to those of estradiol for both the ER and the transport protein SHBG (sex hormone-binding globulin) $[92,93]$. Regional estrogen binding is readily quantified by FES PET, and FES uptake has been validated as a measure of ER expression in breast tumors against ER expression assay of tissue samples by immunohistochemistry [94]. FES uptake is readily visualized and quantified in primary 
breast cancer and MBC [95]. FES PET can identify heterogeneous ER expression [96] (Figure 3). The level of FES uptake has been shown to be predictive of response to endocrine therapy, and early increase in FDG uptake after administration of an ER agonist (metabolic flare) can also predict response to therapy $[97,98]$. Serial FES PET can also measure the pharmacokinetic effect of drugs on estradiol binding to the ER, yielding insights into determinants of drug efficacy, and has potential as an important tool for elucidating mechanisms of endocrine resistance [99]. FES is also an investigational tracer but is poised to be incorporated into multicenter cooperative group trials.

Molecular imaging also provides a unique opportunity to image the tumor microenvironment, which is challenging by more invasive means. Tumor hypoxia is an important factor mediating cancer aggressiveness and therapeutic resistance $[100,101]$ and has gained renewed interest in the setting of increased use of anti-angiogenic therapies and with an improved understanding of aberrant patterns of breast tumor metabolism. Tumor hypoxia has been widely studied by imaging, mostly with PET and the agent ${ }^{18} \mathrm{~F}$-fluoromisonidazole (FMISO) [102,103]; however, other PET hypoxia probes have been developed and tested [104]. These are all investigational agents; however, there is a commercial supplier for FMISO in the US and an NCI-held IND facilitating its use. Other hypoxia imaging methods based upon MRI and optical approaches are in earlier stages of development but also appear promising [105].

An increasingly frequent application of molecular imaging to breast cancer treatment is as a pharmacodynamic measure of response to targeted therapy. Many biologically targeted anti-cancer agents can directly or indirectly affect the pathways of glucose metabolism, transport, and glycolysis, resulting in decreased FDG uptake in tumors with therapy [65]. Molecular imaging modalities, particularly FDG PET, are increasingly incorporated in phase I trials as changes in FDG uptake may provide early evidence of drug activity for many agents in development, such as insulin growth factor pathway (IGF1R) inhibitors, phosphatidylinositol 3-kinase (PI3K), mammalian target of rapamycin (mTOR) inhibitors, and others in which surrogate response biomarkers are not available or require tissue sampling that is not always feasible [106]. With the wide array of tracers capable of imaging of protein expression, tumor proliferation, tumor vascularity, and cell death, molecular imaging is perfectly poised as a surrogate response biomarker.

\section{Conclusions}

Breast cancer is a common disease in women and a leading cause of death. Molecular imaging plays an important role in the detection, diagnosis, staging, and

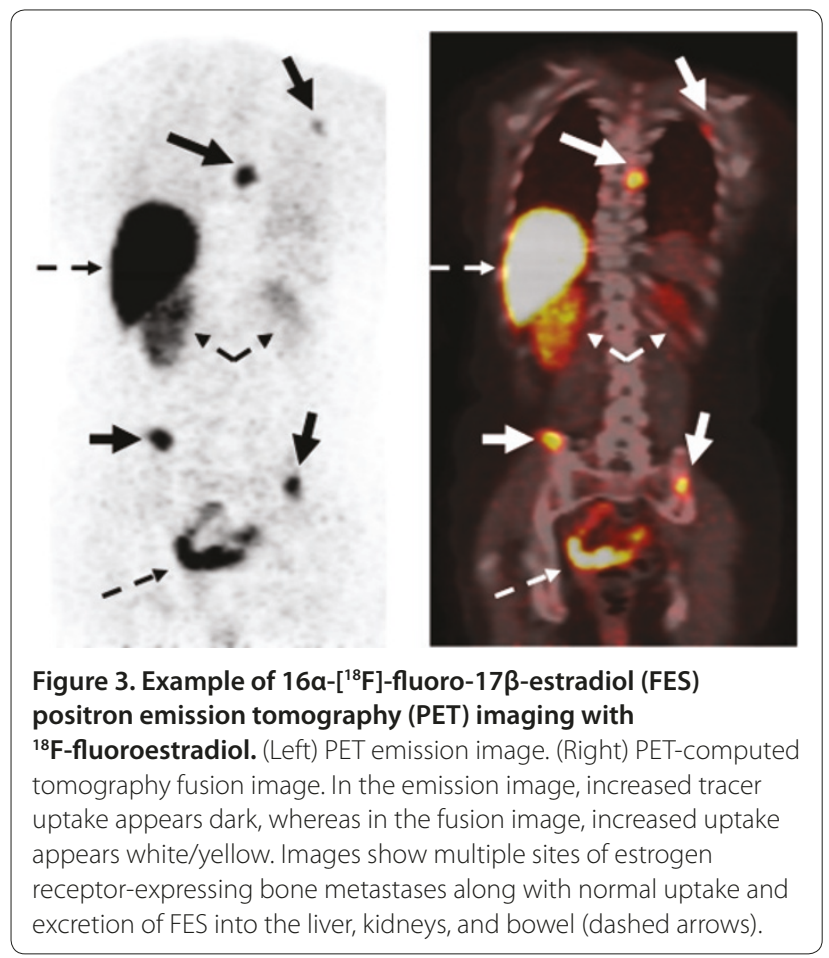

response evaluation of breast cancer. As breast cancer diagnosis and therapies become increasingly molecular and individualized, molecular imaging will play a progressively more important role in breast cancer clinical care. Molecular imaging techniques offer exciting potential to translate tissue-based, genomic discoveries to the clinic and to further the development of new therapeutic agents for breast cancer.

\section{Abbreviations}

BSGl, breast-specific gamma imaging; CT, computed tomography; DCE-MRI, dynamic contrast-enhanced magnetic resonance imaging; ER, estrogen receptor; FDG, ${ }^{18} \mathrm{~F}$-fluorodeoxyglucose; FES, $16 a-\left[{ }^{18} \mathrm{~F}\right]$-fluoro-17 $\beta$-estradiol; FLT, ${ }^{18} \mathrm{~F}$-fluorothymidine; FMISO, ${ }^{18} \mathrm{~F}$-fluoromisonidazole; IND, investigational new drug; $L A B C$, locally advanced breast cancer; MBC, metastatic breast cancer; $\mathrm{MIBI}$, ${ }^{99 m} \mathrm{TC}$-sestamibi; MRI, magnetic resonance imaging; MRS, magnetic resonance spectroscopy; $\mathrm{NCI}$, National Cancer Institute; PEM, positron emission mammography; PET, positron emission tomography; RECIST, Response Evaluation Criteria in Solid Tumors; SPECT, single-photon emission computed tomography; SUV, standard uptake value.

\section{Competing interests}

The authors declare that they have no competing interests.

\section{Acknowledgments}

JMS receives grant support from the National Comprehensive Cancer Network, Pfizer Inc (New York, NY, USA), the Kuni Foundation, Genentech, Inc. (South San Francisco, CA, USA), and Veridex LLC (Raritan, NJ, USA). DAM receives grant support from Merck (Darmstadt, Germany) and Pfizer Inc. This work was funded in part by National Institutes of Health grants CA42045, CA124573, CA138293, and CA148131. The authors thank Lawrence MacDonald and James Rogers for providing PEM images.

\section{Author details}

'Division of Medical Oncology, University of Washington, Seattle Cancer Care Alliance, 825 Eastlake Avenue East, G3-630, Seattle, WA 98109, USA. ${ }^{2}$ Division of Nuclear Medicine, University of Washington, Seattle Cancer Care Alliance, 825 Eastlake Avenue East, G2-600, Seattle, WA 98109, USA. 
Published: 16 March 2012

\section{References}

1. Mankoff DA: A definition of molecular imaging. J Nucl Med 2007, 48:18N, $21 \mathrm{~N}$

2. Benard F, Turcotte E: Imaging in breast cancer: single-photon computed tomography and positron-emission tomography. Breast Cancer Res 2005, 7:153-162.

3. Brem RF, Fishman M, Rapelyea JA: Detection of ductal carcinoma in situ with mammography, breast specific gamma imaging, and magnetic resonance imaging: a comparative study. Acad Radio/ 2007, 14:945-950.

4. Brem RF, Floerke AC, Rapelyea JA, Teal C, Kelly T, Mathur V: Breast-specific gamma imaging as an adjunct imaging modality for the diagnosis of breast cancer. Radiology 2008, 247:651-657.

5. Mankoff DA, Eary JF, Link JM, Muzi M, Rajendran JG, Spence AM, Krohn KA: Tumor-specific positron emission tomography imaging in patients: [18F] fluorodeoxyglucose and beyond. Clin Cancer Res 2007, 13:3460-3469.

6. Rosen EL, Eubank WB, Mankoff DA: FDG PET, PET/CT, and breast cancer imaging. Radiographics 2007, 27 Suppl 1:S215-229.

7. Lehman CD, Smith RA: The role of MRI in breast cancer screening. J Natl Compr Canc Netw 2009, 7:1109-1115.

8. Partridge SC, Vanantwerp RK, Doot RK, Chai X, Kurland BF, Eby PR, Specht JM, Dunnwald LK, Schubert EK, Lehman CD, Mankoff DA: Association between serial dynamic contrast-enhanced MRI and dynamic 18F-FDG PET measures in patients undergoing neoadjuvant chemotherapy for locally advanced breast cancer. J Magn Reson Imaging 2010, 32:1124-1131.

9. Barrett T, Brechbiel M, Bernardo M, Choyke PL: MRI of tumor angiogenesis. J Magn Reson Imaging 2007, 26:235-249.

10. Padhani AR, Leach MO: Antivascular cancer treatments: functional assessments by dynamic contrast-enhanced magnetic resonance imaging. Abdom Imaging 2005, 30:324-341.

11. Wedam SB, Low JA, Yang SX, Chow CK, Choyke P, Danforth D, Hewitt SM Berman A, Steinberg SM, Liewehr DJ, Plehn J, Doshi A, Thomasson D, McCarthy N,Koeppen H, Sherman M, Zujewski J, Camphausen K, Chen H, Swain SM: Antiangiogenic and antitumor effects of bevacizumab in patients with inflammatory and locally advanced breast cancer. J Clin Oncol 2006, 24:769-777.

12. Haddadin IS, McIntosh A, Meisamy S, Corum C, Styczynski Snyder AL, Powell NJ, Nelson MT, Yee D, Garwood M, Bolan PJ: Metabolite quantification and high-field MRS in breast cancer. NMR Biomed 2009, 22:65-76.

13. Meisamy S, Bolan PJ, Baker EH, Bliss RL, Gulbahce E, Everson LI, Nelson MT, Emory TH, Tuttle TM, Yee D, Garwood M: Neoadjuvant chemotherapy of locally advanced breast cancer: predicting response with in vivo (1)H MR spectroscopy--a pilot study at 4 T. Radiology 2004, 233:424-431.

14. Tromberg BJ, Pogue BW, Paulsen KD, Yodh AG, Boas DA, Cerussi AE: Assessing the future of diffuse optical imaging technologies for breast cancer management. Med Phys 2008, 35:2443-2451.

15. Tromberg BJ, Cerussi A, Shah N, Compton M, Durkin A, Hsiang D, Butler J, Mehta R: Imaging in breast cancer: diffuse optics in breast cancer: detecting tumors in pre-menopausal women and monitoring neoadjuvant chemotherapy. Breast Cancer Res 2005, 7:279-285.

16. Bloch SH, Dayton PA, Ferrara KW: Targeted imaging using ultrasound contrast agents. Progess and opportunities for clinical and research applications. IEEE Eng Med Biol Mag 2004, 23:18-29.

17. Mankoff DA, Dunnwald LK, Gralow JR, Ellis GK, Schubert EK, Charlop AW, Tseng J, Rinn KJ, Livingston RB: [Tc-99m]-sestamibi uptake and washout in locally advanced breast cancer are correlated with tumor blood flow. Nucl Med Biol 2002, 29:719-727.

18. Scopinaro F, Schillaci O, Scarpini M, Mingazzini PL, Di Macio L, Banci M, Danieli R, Zerilli M, Limiti MR, Centi Colella A: Technetium-99m sestamibi: an indicator of breast cancer invasiveness. Eur J Nucl Med 1994, 21:984-987

19. Del Vecchio S, Ciarmiello A, Pace L, Potena MI, Carriero MV Mainolfic, Thomas R, D'Aiuto G, Tsuruo T, Salvatore M: Fractional retention of technetium-99m-sestimibi as an index of P-glycoprotein expression in untreated breast cancer patients. J Nucl Med 1997, 38:1348-1351.

20. Liberman M, Sampalis F, Mulder DS, Sampalis JS: Breast cancer diagnosis by scintimammography: a meta-analysis and review of the literature. Breast Cancer Res Treat 2003, 80:115-126.

21. National Comprehensive Cancer Network: NCCN Clinical Practice Guidelines in Oncology: Invasive Breast Cancer Version (Version 2.2011; 01-05-11). Fort Washington, PA: National Comprehensive Cancer Network, Inc:; 2011.
22. Rhodes DJ, Hruska CB, Phillips SW, Whaley DH, O'Connor MK: Dedicated dual-head gamma imaging for breast cancer screening in women with mammographically dense breasts. Radiology 2011, 258:106-118.

23. O'Connor M, Rhodes D, Hruska C: Molecular breast imaging. Expert Rev Anticancer Ther 2009, 9:1073-1080.

24. Alessio AM, Kinahan PE, Cheng PM, Vesselle H, Karp JS: PET/CT scanner instrumentation, challenges, and solutions. Radio/ Clin North Am 2004 42:1017-1032, vii.

25. Eubank WB, Mankoff DA, Schmiedl UP, Winter TC 3rd, Fisher ER, Olshen AB, Graham MM, Eary JF: Imaging of oncologic patients: benefit of combined CT and FDG PET in the diagnosis of malignancy. AJR Am J Roentgenol 1998, 171:1103-1110.

26. Tatsumi M, Cohade C, Mourtzikos KA, Fishman EK, Wahl RL: Initial experience with FDG-PET/CT in the evaluation of breast cancer. Eur J Nucl Med Mol Imaging 2006, 33:254-262.

27. Fueger BJ, Weber WA, Quon A, Crawford TL, Allen-Auerbach MS, Halpern BS, Ratib O, Phelps ME, Czernin J: Performance of 2-deoxy-2-[F-18]fluoro-Dglucose positron emission tomography and integrated $\mathrm{PET} / \mathrm{CT}$ in restaged breast cancer patients. Mol Imaging Biol 2005, 7:369-376

28. Avril N, Menzel M, Dose J, Schelling M, Weber W, Janicke F, Nathrath W, Schwaiger M: Glucose metabolism of breast cancer assessed by 18F-FDG PET: histologic and immunohistochemical tissue analysis. J Nucl Med 2001 42:9-16

29. Bos R, van Der Hoeven JJ, van Der Wall E, van Der Groep P, van Diest PJ, Comans EF, Joshi U, Semenza GL, Hoekstra OS, Lammertsma AA, Molthoff CF: Biologic correlates of (18)fluorodeoxyglucose uptake in human breast cancer measured by positron emission tomography. J Clin Onco/ 2002 20:379-387.

30. Scheidhauer K, Walter C, Seemann MD: FDG PET and other imaging modalities in the primary diagnosis of suspicious breast lesions. Eur J NuCl Med Mol Imaging 2004, 31 Suppl 1:S70-79.

31. Hodgson NC, Gulenchyn KY: Is there a role for positron emission tomography in breast cancer staging? J Clin Oncol 2008, 26:712-720.

32. Raylman RR, Majewski S, Smith MF, Proffitt J, Hammond W, Srinivasan A, McKisson J, Popov V, Weisenberger A, Judy CO, Kross B, Ramasubramanian S, Banta LE, Kinahan PE, Champley K: The positron emission mammography/ tomography breast imaging and biopsy system (PEM/PET): design, construction and phantom-based measurements. Phys Med Bio/ 2008 , 53:637-653.

33. Berg WA, Weinberg IN, Narayanan D, Lobrano ME, Ross E, Amodei L, Tafra L, Adler LP, Uddo J, Stein W 3rd, Levine EA; Positron Emission MammographyWorking Group: High-resolution fluorodeoxyglucose positron emission tomography with compression ('positron emission mammography') is highly accurate in depicting primary breast cancer. Breast J 2006, 12:309-323.

34. Hendrick RE: Radiation doses and cancer risks from breast imaging studies. Radiology 2010, 257:246-253.

35. Rosen EL, Turkington TG, Soo MS, Baker JA, Coleman RE: Detection of primary breast carcinoma with a dedicated, large-field-of-view FDG PET mammography device: initial experience. Radiology 2005, 234:527-534.

36. Berg WA, Madsen KS, Schilling K, Tartar M, Pisano ED, Larsen LH, Narayanan D, Ozonoff A, Miller JP, Kalinyak JE: Breast cancer: comparative effectiveness of positron emission mammography and MR imaging in presurgical planning for the ipsilateral breast. Radiology 2011, 258:59-72.

37. Utech $\mathrm{Cl}$, Young CS, Winter PF: Prospective evaluation of fluorine-18 fluorodeoxyclucose positron emission tomography in breast cancer for staging of the axilla related to surgery and immunocytochemistry. Eur J Nucl Med 1996, 23:1588-1593.

38. Avril N, Dose J, Jänicke F, Bense S, Ziegler S, Laubenbacher C, Römer W, Pache H, Herz M, Allgayer B, Nathrath W, Graeff H, Schwaiger M: Metabolic characterization of breast tumors with positron emission tomography using F-18 fluorodeoxyglucose. J Clin Oncol 1996, 14:1848-1857.

39. Wahl RL, Siegel BA, Coleman RE, Gatsonis CG: Prospective multicenter study of axillary nodal staging by positron emission tomography in breast cancer: a report of the staging breast cancer with PET Study Group. J Clin Oncol 2004, 22:277-285.

40. Carlson RW, Allred DC, Anderson BO, Burstein HJ, Carter WB, Edge SB, Erban JK, Farrar WB, Forero A, Giordano SH, Goldstein LJ, Gradishar WJ, Hayes DF,Hudis CA, Ljung BM, Mankoff DA, Marcom PK, Mayer IA, McCormick B, Pierce LJ, Reed EC, Sachdev J, Smith ML, Somlo G, Ward JH, Wolff AC, Zellars R; National Comprehensive Cancer Network: Invasive breast cancer. J Nat 
Compr Canc Netw 2011, 9:136-222

41. Gil-Rendo A, Zornoza G, Garcia-Velloso MJ, Regueira FM, Beorlegui C, Cervera M: Fluorodeoxyglucose positron emission tomography with sentinel lymph node biopsy for evaluation of axillary involvement in breast cancer. Br J Surg 2006, 93:707-712.

42. Kumar R, Zhuang H, Schnall M, Conant E, Damia S, Weinstein S, Chandra P, Czerniecki B, Alavi A: FDG PET positive lymph nodes are highly predictive of metastasis in breast cancer. Nucl Med Commun 2006, 27:231-236.

43. van der Hoeven JJ, Hoekstra OS, Comans EF, Pijpers R, Boom RP, van Geldere D, Meijer S, Lammertsma AA, Teule GJ: Determinants of diagnostic performance of [F-18]fluorodeoxyglucose positron emission tomography for axillary staging in breast cancer. Ann Surg 2002, 236:619-624.

44. Bellon JR, Livingston RB, Eubank WB, Gralow JR, Ellis GK, Dunnwald LK, Mankoff DA: Evaluation of the internal mammary lymph nodes by FDG-PET in locally advanced breast cancer (LABC). Am J Clin Oncol 2004, 27:407-410

45. Whelan TJ, Olivotto I, Ackerman I, Chapman JW, Chua B, Nabid A, Vallis KA, White JR, Rousseau P, Fortin A, Pierce LJ, Manchul L, Craighead P, Nolan MC, Bowen J, McCready DR, Pritchard KI, Levine MN, Parulekar W: NCIC-CTG MA.20: an intergroup trial of regional nodal irradiation in early breast cancer. J Clin Oncol 2011, 29:(suppl). Abstract LBA1003.

46. Isasi CR, Moadel RM, Blaufox MD: A meta-analysis of FDG-PET for the evaluation of breast cancer recurrence and metastases. Breast Cancer Res Treat 2005, 90:105-112.

47. Eubank WB, Mankoff D, Bhattacharya M, Gralow J, Linden H, Ellis G, Lindsley S, Austin-Seymour M, Livingston R: Impact of FDG PET on defining the extent of disease and on the treatment of patients with recurrent or metastatic breast cancer. AJR Am J Roentgenol 2004, 183:479-486

48. Kamel EM, Wyss MT, Fehr MK, von Schulthess GK, Goerres GW: [18F]-Fluorodeoxyglucose positron emission tomography in patients with suspected recurrence of breast cancer. J Cancer Res Clin Oncol 2003, 129:147-153.

49. Moon DH, Maddahi J, Silverman DH, Glaspy JA, Phelps ME, Hoh CK: Accuracy of whole-body fluorine-18-FDG PET for the detection of recurrent or metastatic breast carcinoma. J Nucl Med 1998, 39:431-435.

50. Lee JH, Rosen EL, Mankoff DA: The role of radiotracer imaging in the diagnosis and management of patients with breast cancer: part 2--response to therapy, other indications, and future directions. J Nucl Med 2009, 50:738-748.

51. Rousseau C, Devillers A, Sagan C, Ferrer L, Bridji B, Campion L, Ricaud M, Bourbouloux E, Doutriaux I, Clouet M, Berton-Rigaud D, Bouriel C, Delecroix V,Garin E, Rouquette S, Resche I, Kerbrat P, Chatal JF, Campone M: Monitoring of early response to neoadjuvant chemotherapy in stage II and III breast cancer by [18F]fluorodeoxyglucose positron emission tomography. J Clin Oncol 2006, 24:5366-5372.

52. Berriolo-Riedinger A, Touzery C, Riedinger JM, Toubeau M, Coudert B, Arnould L, Boichot C, Cochet A, Fumoleau P, Brunotte F: [18F]FDG-PET predicts complete pathological response of breast cancer to neoadjuvant chemotherapy. Eur J Nucl Med Mol Imaging 2007, 34:1915-1924.

53. Dose Schwarz J, Bader M, Jenicke L, Hemminger G, Janicke F, Avril N: Early prediction of response to chemotherapy in metastatic breast cancer using sequential 18F-FDG PET. J Nucl Med 2005, 46:1144-1150.

54. Avril N, Sassen S, Roylance R: Response to therapy in breast cancer. J NuCl Med 2009, 50 Suppl 1:55S-63S.

55. Therasse P, Arbuck SG, Eisenhauer EA, Wanders J, Kaplan RS, Rubinstein L Verweij J, Van Glabbeke M, van Oosterom AT, Christian MC, Gwyther SG: New guidelines to evaluate the response to treatment in solid tumors. European Organization for Research and Treatment of Cancer, National Cancer Institute of the United States, National Cancer Institute of Canada. J Natl Cancer Inst 2000, 92:205-216.

56. Eisenhauer EA, Therasse P, Bogaerts J, Schwartz LH, Sargent D, Ford R, Dancey I, Arbuck S, Gwyther S, Mooney M, Rubinstein L, Shankar L, Dodd L, Kaplan R, Lacombe D, Verweij J: New response evaluation criteria in solid tumours: revised RECIST guideline (version 1.1). Eur J Cancer 2009, 45:228-247.

57. Wahl RL, Jacene H, Kasamon Y, Lodge MA: From RECIST to PERCIST: evolving considerations for PET response criteria in solid tumors. J Nucl Med 2009, 50 Suppl 1:122S-150S

58. Hamaoka T, Madewell JE, Podoloff DA, Hortobagyi GN, Ueno NT: Bone imaging in metastatic breast cancer. J Clin Oncol 2004, 22:2942-2953.

59. Schneider JA, Divgi CR, Scott AM, Macapinlac HA, Seidman AD, Goldsmith SJ, Larson SM: Flare on bone scintigraphy following Taxol chemotherapy for metastatic breast cancer. J Nucl Med 1994, 35:1748-1752.

60. Stafford SE, Gralow JR, Schubert EK, Rinn KJ, Dunnwald LK, Livingston RB, Mankoff DA: Use of serial FDG PET to measure the response of bonedominant breast cancer to therapy. Acad Radiol 2002, 9:913-921.

61. Specht JM, Tam SL, Kurland BF, Gralow JR, Livingston RB, Linden HM, Ellis GK, Schubert EK, Dunnwald LK, Mankoff DA: Serial 2-[18F] fluoro-2-deoxy-Dglucose positron emission tomography (FDG-PET) to monitor treatment of bone-dominant metastatic breast cancer predicts time to progression (TTP). Breast Cancer Res Treat 2007, 105:87-94

62. Tateishi U, Gamez C, Dawood S, Yeung HW, Cristofanilli M, Macapinlac HA: Bone metastases in patients with metastatic breast cancer: morphologic and metabolic monitoring of response to systemic therapy with integrated PET/CT. Radiology 2008, 247:189-196.

63. Cook GJ, Houston S, Rubens R, Maisey MN, Fogelman I: Detection of bone metastases in breast cancer by 18FDG PET: differing metabolic activity in osteoblastic and osteolytic lesions. J Clin Oncol 1998, 16:3375-3379.

64. Doot RK, Muzi M, Peterson LM, Schubert EK, Gralow JR, Specht JM, Mankoff DA: Kinetic analysis of 18F-fluoride PET images of breast cancer bone metastases. J Nucl Med 2010, 51:521-527

65. Kelloff GJ, Krohn KA, Larson SM, Weissleder R, Mankoff DA, Hoffman JM, Link JM, Guyton KZ, Eckelman WC, Scher HI, O'Shaughnessy J, Cheson BD, Sigman CC, Tatum JL, Mills GQ, Sullivan DC, Woodcock J: The progress and promise of molecular imaging probes in oncologic drug development. Clin Cancer Res 2005, 11:7967-7985.

66. Dunnwald LK, Gralow JR, Ellis GK, Livingston RB, Linden HM, Specht JM, Doot RK, Lawton TJ, Barlow WE, Kurland BF, Schubert EK, Mankoff DA: Tumor metabolism and blood flow changes by positron emission tomography: relation to survival in patients treated with neoadjuvant chemotherapy for locally advanced breast cancer. J Clin Oncol 2008, 26:4449-4457.

67. Mankoff DA, Dunnwald LK, Gralow JR, Ellis GK, Charlop A, Lawton TJ, Schubert EK, Tseng J, Livingston RB: Blood flow and metabolism in locally advanced breast cancer: relationship to response to therapy. J Nucl Med 2002, 43:500-509.

68. Mankoff DA, Dunnwald LK, Gralow JR, Ellis GK, Schubert EK, Tseng J, Lawton TJ, Linden HM, Livingston RB: Changes in blood flow and metabolism in locally advanced breast cancer treated with neoadjuvant chemotherapy. J Nucl Med 2003, 44:1806-1814.

69. Ah-See ML, Makris A, Taylor NJ, Harrison M, Richman PI, Burcombe RJ, Stirling JJ, d'Arcy JA, Collins DJ, Pittam MR, Ravichandran D, Padhani AR: Early changes in functional dynamic magnetic resonance imaging predict for pathologic response to neoadjuvant chemotherapy in primary breast cancer. Clin Cancer Res 2008, 14:6580-6589.

70. Li SP, Makris A, Beresford MJ, Taylor NJ, Ah-See ML, Stirling JJ, d'Arcy JA, Collins DJ, Kozarski R, Padhani AR: Use of dynamic contrast-enhanced MR imaging to predict survival in patients with primary breast cancer undergoing neoadjuvant chemotherapy. Radiology 2011, 260:68-78.

71. Miles KA, Williams RE: Warburg revisited: imaging tumour blood flow and metabolism. Cancer Imaging 2008, 8:81-86.

72. Wang Y, Dan HJ, Fan JH, Wen SB: Evaluation of the correlation between colour power Doppler flow imaging and vascular endothelial growth factor in breast cancer. J Int Med Res 2010, 38:1077-1083.

73. Singh G, Kumar P, Parshad R, Seith A, Thulkar S, Hosten N: Role of color Doppler indices in predicting disease-free survival of breast cancer patients during neoadjuvant chemotherapy. Eur J Radio/ 2010, 75:e158-162.

74. Beer AJ, Carlsen J, Sarbia M, Nahrig J, Watzlowid P, Wester HJ, Harbeck N, Schwaiger M: Patterns of alphavbeta3 expression in primary and metastatic human breast cancer as shown by $18 \mathrm{~F}-$ Galacto-RGD PET. J NuCl Med 2008, 49:255-259.

75. Contractor KB, Kenny LM, Stebbing J, Al-Nahhas A, Palmieri C, Sinnett D, Lewis JS, Hogben K, Osman S, Shousha S, Lowdell C, Coombes RC, Aboagye EO: [11C]choline positron emission tomography in estrogen receptor-positive breast cancer. Clin Cancer Res 2009, 15:5503-5510.

76. Moestue SA, Borgan E, Huuse EM, Lindholm EM, Sitter B, Borresen-Dale AL, Engebraaten O, Maelandsmo GM, Gribbestad IS: Distinct choline metabolic profiles are associated with differences in gene expression for basal-like and luminal-like breast cancer xenograft models. BMC Cancer 2010, 10:433.

77. Tannock IF, Hill RP (Eds): The Basic Science of Oncology. Amsterdam: Elsevier Science; 1992

78. Cleaver JE: Thymidine Metabolism and Cell Kinetics. Volume6. Amsterdam: North-Holland Publishing Company; 1967.

79. Pinder SE, Wencyk P, Sibbering DM, Bell JA, Elston CW, Nicholson R, Robertson 
JF, Blamey RW, Ellis IO: Assessment of the new proliferation marker MIB1 in breast carcinoma using image analysis: associations with other prognostic factors and survival. Br J Cancer 1995, 71:146-149.

80. Yerushalmi R, Woods R, Ravdin PM, Hayes MM, Gelmon KA: Ki67 in breast cancer: prognostic and predictive potential. Lancet Oncol 2010, 11:174-183.

81. Dowsett M, Smith IE, Ebbs SR, Dixon JM, Skene A, A'Hern R, Salter J, Detre S, Hills M, Walsh G: Prognostic value of Ki67 expression after short-term presurgical endocrine therapy for primary breast cancer. J Natl Cancer Inst 2007, 99:167-170

82. Mankoff DA, Eary JF: Proliferation imaging to measure early cancer response to targeted therapy. Clin Cancer Res 2008, 14:7159-7160

83. Kenny L, Coombes RC, Vigushin DM, Al-Nahhas A, Shousha S, Aboagye EO: Imaging early changes in proliferation at 1 week post chemotherapy: a pilot study in breast cancer patients with $3^{\prime}$-deoxy-3'-[18F] fluorothymidine positron emission tomography. Eur J Nucl Med Mol Imaging 2007, 34:1339-1347.

84. Kenny LM, Contractor KB, Stebbing J, Al-Nahhas A, Palmieri C, Shousha S, Coombes RC, Aboagye EO: Altered tissue 3'-deoxy-3'-[18F]fluorothymidine pharmacokinetics in human breast cancer following capecitabine treatment detected by positron emission tomography. Clin Cancer Res 2009, 15:6649-6657.

85. Mankoff DA, Shields AF, Krohn KA: PET imaging of cellular proliferation. Radiol Clin North Am 2005, 43:153-167.

86. Jolles PR, Kostakoglu L, Bear HD, Idowu MO, Kurdziel KA, Shankar L, Mankoff DA, Duan F, L'Heureux D: ACRIN 6688 phase II study of fluorine-18 3'-deoxy-3' fluorothymidine (FLT) in invasive breast cancer. J Clin Oncol 2011, 29:(suppl). Abstract TPS125.

87. Jordan VC, Brodie AM: Development and evolution of therapies targeted to the estrogen receptor for the treatment and prevention of breast cancer. Steroids 2007, 72:7-25.

88. Slamon DJ, Leyland-Jones B, Shak S, Fuchs H, Paton V, Bajamonde A, Fleming T, Eiermann W, Wolter J, Pegram M, Baselga J, Norton L: Use of chemotherapy plus a monoclonal antibody against HER2 for metastatic breast cancer that overexpresses HER2. N Eng/ J Med 2001, 344:783-792.

89. Mankoff DA, Link JM, Linden HM, Sundararajan L, Krohn KA: Tumor receptor imaging. J Nucl Med 2008, 49 Suppl 2:149S-163S.

90. Quon A, Gambhir SS: FDG-PET and beyond: molecular breast cancer imaging. J Clin Oncol 2005, 23:1664-1673.

91. Katzenellenbogen JA, Welch MJ, Dehdashti F: The development of estrogen and progestin radiopharmaceuticals for imaging breast cancer. Anticancer Res 1997, 17:1573-1576.

92. Kiesewetter DO, Kilbourn MR, Landvatter SW, Heiman DF, Katzenellenbogen $J A$, Welch MJ: Preparation of four fluorine-18-labeled estrogens and their selective uptakes in target tissues of immature rats. J Nucl Med 1984, 25:1212-1221.

93. Tewson TJ, Mankoff DA, Peterson LM, Woo I, Petra P: Interactions of 16alpha[18F]-fluoroestradiol (FES) with sex steroid binding protein (SBP). Nucl Med Biol 1999, 26:905-913.

94. Peterson LM, Mankoff DA, Lawton T, Yagle K, Schubert EK, Stekhova S, Gown A, Link JM, Tewson T, Krohn KA: Quantitative imaging of estrogen receptor expression in breast cancer with PET and 18F-fluoroestradiol. J Nucl Med 2008, 49:367-374.
95. Dehdashti F, Mortimer JE, Siegel BA, Griffeth LK, Bonasera TJ, Fusselman MJ Detert DD, Cutler PD, Katzenellenbogen JA, Welch MJ: Positron tomographic assessment of estrogen receptors in breast cancer: comparison with FDG-PET and in vitro receptor assays. J Nucl Med 1995, 36:1766-1774.

96. Kurland BF, Peterson LM, Lee JH, Linden HM, Schubert EK, Dunnwald LK, Link $\mathrm{JM}$, Krohn KA, Mankoff DA: Between-patient and within-patient (site-tosite) variability in estrogen receptor binding, measured in vivo by 18F-fluoroestradiol (FES) PET. J Nucl Med 2011, 52:1541-1549.

97. Dehdashti F, Mortimer JE, Trinkaus K, Naughton MJ, Ellis M, Katzenellenbogen JA, Welch MJ, Siegel BA: PET-based estradiol challenge as a predictive biomarker of response to endocrine therapy in women with estrogenreceptor-positive breast cancer. Breast Cancer Res Treat 2009, 113:509-517.

98. Mortimer JE, Dehdashti F, Siegel BA, Trinkaus K, Katzenellenbogen JA, Welch MJ: Metabolic flare: indicator of hormone responsiveness in advanced breast cancer. J Clin Oncol 2001, 19:2797-2803.

99. Linden HM, Kurland BF, Peterson LM, Schubert EK, Gralow JR, Specht JM, Ellis GK, Lawton TJ, Livingston RB, Petra PH, Link JM, Krohn KA, Mankoff DA: Fluoroestradiol positron emission tomography reveals differences in pharmacodynamics of aromatase inhibitors, tamoxifen, and fulvestrant in patients with metastatic breast cancer. Clin Cancer Res 2011, 17:4799-4805.

100. Sutherland RM: Tumor hypoxia and gene expression--implications for malignant progression and therapy. Acta Oncol 1998, 37:567-574.

101. Teicher BA: Hypoxia and drug resistance. Cancer Metastasis Rev 1994, 13:139-168.

102. Rajendran JG, Mankoff DA, O'Sullivan F, Peterson LM, Schwartz DL, Conrad EU, Spence AM, Muzi M, Farwell DG, Krohn KA: Hypoxia and glucose metabolism in malignant tumors: evaluation by [18F]fluoromisonidazole and [18F]fluorodeoxyglucose positron emission tomography imaging. Clin Cancer Res 2004, 10:2245-2252.

103. Yang M, Gao H, Sun X, Yan Y, Quan Q, Zhang W, K AM, Rosenblum MG, Niu G, Chen X: Multiplexed PET probes for imaging breast cancer early response to VEGF/rGel treatment. Mol Pharm 2011, 8:621-628.

104. Tatum JL, Kelloff GJ, Gillies RJ, Arbeit JM, Brown JM, Chao KS, Chapman JD, Eckelman WC, Fyles AW, Giaccia AJ, Hill RP, Koch CJ, Krishna MC, Krohn KA,Lewis JS, Mason RP, Melillo G, Padhani AR, Powis G, Rajendran JG, Reba R, Robinson SP, Semenza GL, Swartz HM, Vaupel P, Yang D, Croft B, Hoffman J,Liu $G$, Stone H, Sullivan D: Hypoxia: importance in tumor biology, noninvasive measurement by imaging, and value of its measurement in the management of cancer therapy. Int J Radiat Bio/ 2006, 82:699-757.

105. Padhani A: Science to practice: what does MR oxygenation imaging tell us about human breast cancer hypoxia? Radiology 2010, 254:1-3.

106. Kurdziel K, Ravizzini G, Croft B, Tatum J, Choyke P, Kobayashi H: The evolving role of nuclear molecular imaging in cancer. Expert Opin Med Diagn 2008, 2:829-842.

doi:10.1186/bcr3094

Cite this article as: Specht JM, Mankoff DA: Advances in molecular imaging for breast cancer detection and characterization. Breast Cancer Research 2012, 14:206 